\title{
Ecologically Sustainable Implementations in Contemporary Fashion Design
}

\author{
Tang Qian, Chen Ying* \\ Fashion Design and Engineering, Shanghai University of Engineering Science, Shanghai, China
}

Email address:

chenying39@126.com (Chen Ying)

To cite this article:

Tang Qian, Chen Ying. Ecologically Sustainable Implementations in Contemporary Fashion Design. International Journal of Literature and Arts. Vol. 3, No. 6, 2015, pp. 158-161. doi: 10.11648/j.ijrse.20150404.16

\begin{abstract}
Clothing is not only a necessity in modern life, but also a consumable to satisfy customers' demands. People nowadays cannot live without the need for clothing. The number of spare clothes has increased dramatically due to the fact that consumers have a natural tendency to purchase clothes impulsively. The spare clothes that are left idle annually have resulted in a considerable waste of resources. The synthetic fiber fabrics used in clothes come from oil refineries. Even the natural fabrics utilized in the production process, which are not easy to break down, will inevitably generate massive air pollution and water contamination, causing severe damage to the environment. In order to alleviate the situation, we as fashion designers must bear in mind to adopt the concept of Ecologically Sustainable Development (ESD). From the perspectives of careful clothing fabric selection, clothes recycling and multi-use clothing, the applications that realize the concept of ESD in contemporary fashion design have been assessed and analyzed. It is concluded that the ecological sustainable contemporary clothing design should pay close attention to the clothing fabric used throughout the production. Specifically, one needs to choose fabric materials that are environmentally friendly, and make effective utilization of the fabric.
\end{abstract}

Keywords: Ecology, Sustainability, Contemporary, Fashion Design

\section{Introduction}

In the face of natural disasters reoccurring frequently, shortage of global resources, and environmental pollution getting worse, environmental issues have become the focus of the world's attention. ESD has gradually become prevalent in the whole world. Clothing, as the No.1 life necessity among others, have been substantially influencing customer values, pushing the frontier of ESD. The paper concentrates on studying and discussing this problem, aiming to put ESD into practice. The paper starts out by describing the caveat of fabric selection. One should always select natural organic fabric materials and recyclable regenerative fabrics. Recycling the fabrics is conducive to recycling and reusing of the old clothes. Decomposing and restructuring the recycled fabrics can be beneficial in reducing their environmental impact. Fashion designers may design multifunctional clothes to suit a variety of purposes, at the mean time; they should use the fabric effectively to make contribution for building a sustainable ecological environment.

\section{Ecologically Sustainable Fabric}

Human beings have long been aware of the significance of the environment and strived to search for environmental friendly clothing solutions. Traced back to the origin of clothing materials, the initial clothing material was derived from nature, such as cotton, linen, wool and silk. With the progress of science and technology, in order to meet the ever-increasing demand for clothing, a huge amount of synthetic clothing fiber has been put into production. The main source of the fiber is oil, which is not easy to degrade naturally. And environmental protection of the natural fabrics also produces chemical pollution in the dyeing process. There are problems in the production of chemical fiber chemical residue treatment, old problem of the degradation of polyester and chemical fiber the source of the problem. All of these will cause damage to the environment, long-term wearing polyester will also affect people's health. Fabric as one of the important factors in clothing design, face the present situation, the clothing design's first step is to choose the ecological sustainable fabrics. Due to the developed science and technology, 
contemporary ecological sustainable fabrics not only in natural extracted natural fabrics, but also in non-traditional clothing fabric material extracted the regeneration of the recycled fabrics.

\subsection{Organic Material}

Environmental protection material, just as its name implies is refers to the natural, energy saving, no pollution, can be recycled fabrics. Natural cotton, linen, wool, silk has been recognized as the environmental protection material. Due to environmental concerns in recent years, the traditional fabric was picked up again, show the world in a new form. Contemporary ecological sustainable fabric is basis of traditional natural fabric, discover the new natural organic material. In recent years popular organic natural colored cotton, for instance, Compared with other varieties, Natural colored cotton insect sterilization, more do not need to use chemical fertilizers and pesticides, is the ideal close skin clothing material, especially suitable for baby clothes. This kind of fabric can be directly applied to fashion design. Stella James is designed according to the features of natural colored cotton knitted children's wear, the rendered color is natural form, but also has natural flame retardancy. There are organic cotton, organic silk, wool and other natural material, the fabrics of these natural materials, environmental protection and renewable recycling, is the ideal to the contemporary fashion design of ecological sustainable fabrics. There are bamboo fiber,leaf fiber,corn fiber, soybean fiber. The bamboo fiber is strong and durable, good permeability, anti-static, Compared with other natural fiber, bamboo fiber clothes in the summer, can reduce surface temperature $1^{\circ} \mathrm{C} \sim 2^{\circ} \mathrm{C}$, also can block ultraviolet light, and has the characteristics applied to fashion design, extensive use of suit to sportswear and sunscreen wear[1].

\subsection{Cycle Regeneration of Fabrics}

Of high-tech research and development, and also showed some new environmental protection material. For example, REPT fabrics (recycled polyester), was known as the "coke bottle green cloth". This material is recycled coke bottles, to clean, slice, dissolved, for spinning [2]. NIKE, Adidas and other world famous sports brands are starting to adopt the new environmental protection material. And there are made of drank coffee grounds coffee carbon fiber. The outdoor clothing brand Timberland designer made from this kind of carbon fiber"the most environmentally friendly jacket" [3].If we want to apply the concept of ecological sustainable contemporary fashion design, designers should try to use the sustainable development of ecological fabrics, attaches great importance to environmental protection, the necessity of fabric, create a new ecological sustainable regeneration of fabrics. Both natural fabrics, and build a new type of fabric, is to promote the sustainable development of ecological environmental protection material, they shall be of good use to the costume design.

\section{The Recycling of Old Clothes}

In today's high-speed development of human society, "fast" has become the pronoun of our times. The contemporary people pay a attention to fashion, and popular cycle is short, updated quickly, Under the influence of the "fast" fashion, Spare clothes under impulsive spending has increased dramatically, Spare clothes don't know how to deal with each year, a waste of resources. Basically the choice for sustainable fabrics, use of spare clothing, which recycling and reduce waste materials, but also reduce environmental pollution which can not degrade naturally caused.

\subsection{Old Clothes Again}

For designers, the difference between design and redesign, to design more easily. Redesign is in color, design, fabrics are already have, only on the original color, style and fabric take its essence, let old clothes look brand-new, reconstruction of new clothing design. Social spare old clothes to handle attaches great importance to in recent years, for example, a charity company Traid, by collecting old clothes, recycle, redesign, or recycling, design new clothing styles[4].

\subsubsection{Embroidery}

Embroidery is a design technique of the icing on the cake, applying it to an ordinary old clothes, old clothes look brandnew. (Figure 1) designer Rachael Cassar design a recycled material dress, This skirt $90 \%$ of the materials are made from recycled fabrics. The bottom layer is a mixture of nylon and Lycra fabric, the outer layer is made out of Indian cotton crocheted lace with beads linked to a variety of fabrics, it looks elegant,never see a second transformation[5].

\subsubsection{Hand-painted}

In the contemporary fashion design, hand-painted has become a symbol of personalization. On an old garment DIY hand-painted, energy conservation and environmental protection not only, more can stimulate the creativity and diversity of expression, artistic sense is strong, enhance the taste of the old clothes to the transformation.

\subsubsection{Dyeing}

The characteristics of the different fabrics dyeing are more phyletic, used in dyeing in a different way. Dyeing and transformation of old clothes color. Anand Kabra used a tiedyed way, the impact of indigo blue and yellow, will be a simple loose skirt, become highly visual impact, full of fashionable feeling[6].

\subsubsection{Printing}

Because digital printing is the dye solution directly in a special box on-demand jet on the clothing fabric, do not waste, and no waste water pollution, put an end to the mixing between printing machine wash and discharge of dye solution, no pollution to printing process.Also saves material such as film, wire mesh, silver copper consumption, saving, and environmental protection [7].The digital printing has become a trend in fashion, conform to the sustainable development 
trend of The Times.

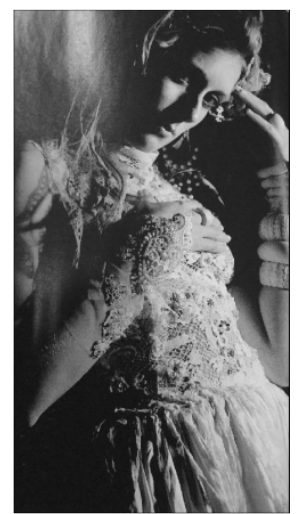

Figure 1. designer Rachael Cassar dress design.

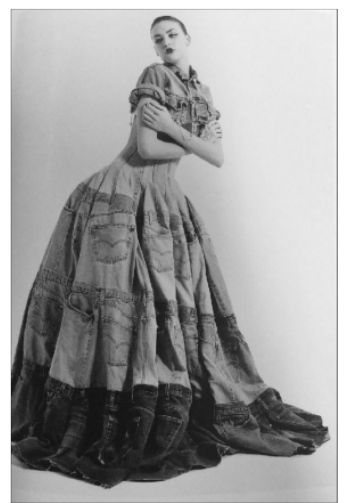

Figure 2. Gary Harvey design of recycled denim skirt.

\subsection{Old Clothes to Create}

Another type of reuse of old clothes, is the use of old clothes designer colors, design, fabrics for complete separation, deconstruction, whichever is the inspiration for the design elements, and then to combination, to create a variety of colors, a variety of styles, and a variety of fabrics coupled with new design, so that once the clothes back to life, creating a unique and stylish and environmentally friendly clothing. Such a re-creation initiatives, the material was used clothes of the best use of ecologically sustainable development and a significant contribution, at the same time for the designer, also give designers much more creative space to stimulate more much inspiration and creativity, either follow the trend, but also environmental protection. (Figure 2) Designer Gary Harvey recycling jeans to transform the use of subtle changes in different color jeans, will more than jeans joining together of deconstruction in the depth of the color order, according to the properties of hard fabrics jeans, designed a bull-puncher skirt have slip model. [8]Such a design method of decomposition and then joining together, by the designers. Architect Antoine. Peters, recyclable cotton sweater knitting, knitting, formed a large group of colorful sweater. Gary Harvey. Creative company use the concept of sustainable design a concept of evening wear, is more retro windbreaker assembly,integration,the use of the coat of drape and water proof fabric characteristics.

\section{4. "A Clothes Wear More" Design}

According to a statistics, the textile industry in Europe and the United States alone, the textile industry to waste a year textile fabrics has been close to 100000 tons of [9]. Typically, a garment in the production process is $15 \%$ of the fabric is waste [10]. Based on the concept of sustainable increase of fabric, and the modern clothing, clothing design of ecological sustainable development also has an important role."The clothes wear more" clothing design is the design concept of ecological sustainable. For "the clothes wear more" design concept, there are two kinds of interpretation, "seeking common ground" "reserving differences".

\subsection{General Clothing of "A Multi-wear Clothes"}

The so-called general clothing of "the clothes wear more", is a piece of clothing can be common in people of different age and different occasions and different form of a design of the human body. Take the "the clothes wear more" is "seeking common ground". From the perspective of the age, "accommodationist" is wearing clothes of all ages in common, the fuzzy boundaries of all ages, make its adjacent ages of clothing are interchangeable in collocation, reduce the age subdivision, design clothing that gm in different age groups, reduce the waste of resources; From the point of view of occasions, "accommodationist" is in different occasions, wearing clothes in common, such as the work of the professional attire, casual entertainment, party of clothing, such as different occasions, wearing clothing type, clothing like dresses, wearing a few times, of waste caused by clothes. This requires designers take on different occasions dress in common, a universal design clothes in different occasion, is advantageous to the clothing enterprise to carry on the unification of the batch production, reduce the waste of spare clothes. From the point of view of form, "accommodationist" is take different bodily form feature in the design of clothing, each person's body is different, by measuring the different form of clothing sizes, movement range, etc., design a general in the design of different forms of clothing style. General clothing"the clothes wear more" design, expand the scope of adapt to the crowd, enhance the practicability of clothes.

\section{2. "More Change Clothes Wear More"}

Many changes"The clothes wear more" is on a piece of clothing,"while reserving differences". A clothes wear more, is a piece of clothing, by changing its original clothing structure, break the conventional thinking, through the different deformation, disassembly, transformation can change a variety of dress styles. This design has greatly increased the utilization rate of the clothes, functionality and design feeling, is has very strong practicability of fashion design. As early as 1990 famous designer sichuan long bao ling has devised the concept of "the clothes wear more"clothes.( figure 3) The concept of clothes like on a piece of fabric cut a lot of small openings, all do not like a garment, the wearer can choose to arm through any openings, 
casual wear, the inspiration of this oncept has inspired many designers. As people awareness of environmental protection to strengthen in recent years, now the consumer more from several aspects to choose to buy clothes. Such as the price of clothes, design, creative, clipping, fabrics, and functional and practical, etc. While the clothes wear more clothing design is to meet the multiple demands of consumers, for consumers to buy value of clothing, also reflected the concept of ecological and sustainable. Designer Donna karan called a variety of tees in the queen, she designed a DKNY Cozy -- "the clothes wear more" sweater, through a variety of twisted into a different style of "new clothes". (figure 4)there may be turned handbags, through expansion into a single shoulder bag, oversized daily packages or oblique cross draw string of the parcel. She also claims to have launched a one million kind worn "unlimited dress"[11].

"The clothes wear more"clothing design, improve the utilization rate of fabric will maximization, cost savings, reduce the waste of resources, this kind of clothing is the combination of function and aesthetic feeling, also give the wearer individuality experience at the same time, meet the different needs of the wearer, let consumers feel the joy of the game of clothes in the concept of environmental protection, reduce the number of buying new clothes, virtually involved in the ranks of environmental protection.

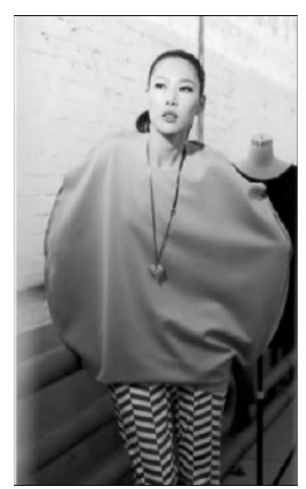

Figure 3. sichuan long bao ling design works of "the clothes wear more".

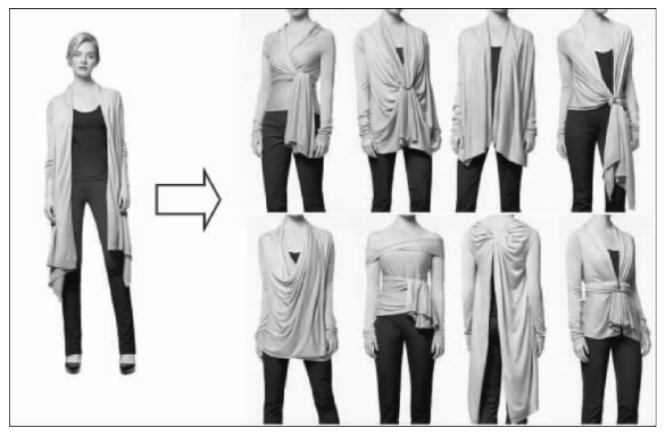

Figure 4. Donna karan design of DKNY Cozy.

\section{Conclusion}

This paper incorporates the concept of ESD into the contemporary fashion design. Fashion designers are urged to adopt natural clothing fabrics, discover new sustainable material along the way, as well as endeavor recycling old clothes. In addition, they need to become more aware of the methodology of creating new sustainable clothes based on modification to the old ones. Fashion designers should put the concept of ESD into practice while designing clothes to achieve the best of both worlds - fabulous design and environment protection.

Contemporary ecologically sustainable clothing design focuses on the styling and practicality of the clothes. Designers should go through a range of innovative designs and clothing reuse strategies, and make reasonable and effective use of the limited clothing fabrics to fulfill sustainability and contribute to the idea of ESD.

\section{References}

[1] Wang Hong, Xuming Zhu Introduction to fabrics to create and costume design $[\mathrm{J}]$. Journal of textile science and technology progress, $2010(5): 74$

[2] Lina Fu. Fabric construction and application in the clothing design $[\mathrm{J}]$. Journal of Zhejiang textile vocational technology college, $2010(6): 33$.

[3] Xiaogang Liu, Gehui Wang. Design of clothing materials [J]. Shanghai: Donghua university press, 2010.12

[4] Zengchao Liu. Cultural harmonious environmental ethics and sustainable development [M].Xi 'an: northwest agriculture and forestry university of science and technology press, 2012:55-6.

[5] Changming Liu. The cultural ecological environment [M]. Beijing: press of concentric, 2007:37 to 40 .

[6] Zhao Yu. Apparel industry, environmental research [D]. Master's degree thesis. Tianjin Polytechnic University .2007

[7] Jiewen Zhou. Green costume design. [J]. Silk .2002:61-63

[8] Zhang Zheng. Leixiao Wang . Foreign waste recycling costume design situation. Tianjin Textile Science and Technology. Section 191.2010

[9] Jiangyou Wang. Textiles loop processing and re-use [H]. Beijing. China Textile Press (2008)

[10] Xing Xu. High-tech fabrics and clothing design new ideas and technological progress. 2001: 42-45

[11] Chengdong Mao. Development trend of ecological fabric of Tianjin Textile Technology. 2006: 58-89 